\title{
Influence of Chloride on Passive Film Chemistry of 304 Stainless Steel in Sulphuric Acid Solution by Glow Discharge Optical Emission Spectrometry Analysis
}

\author{
Saifu Deng, Shuangbao Wang ${ }^{*}$, Linyue Wang, Jianting Liu, Yujie Wang \\ School of Optics and Electronic Information, Huazhong University of Science \& Technology, Wuhan \\ 430074, China \\ *E-mail: shuangbaowang@126.com
}

doi: $10.20964 / 2017.02 .43$

Received: 14 November 2016 / Accepted: 19 December 2016 / Published: 30 December 2016

\begin{abstract}
The influence of chloride on passive film formed on 304 stainless steels (SS) in $0.2 \mathrm{M} \mathrm{H}_{2} \mathrm{SO}_{4}$ solution has been investigated by potentiostatic polarization experiments and glow discharge optical emission spectroscopy (GD-OES) analysis. Chromium was enriched in outer and inner layers of passive film after potentiostatic passivation. The $\mathrm{Cr} / \mathrm{Fe}$ ratio of the passive film increased with immersion time of passivation, which suggested the improvement of corrosion resistance. The breakdown of passivity was evaluated by addition of sodium chloride $(\mathrm{NaCl})$. Pitting corrosion appeared on the surface of the passive film when $3 \mathrm{wt} \%$ of $\mathrm{NaCl}$ was added into the solution, thereby resulting in a decrease of iron species in the outer layer of the passive film. The depth profiles showed the appearance of chlorine in the passive film region of 304 SS polarized in chloride-containing solution. The decrease of $\mathrm{Cl}$ species intensity from the outer layer to the inner layer validated the penetration of chloride ions through passive film during pitting corrosion.
\end{abstract}

Keywords: 304 stainless steel, GD-OES, passive film, pitting corrosion.

\section{FULL TEXT}

(C) 2017 The Authors. Published by ESG (www.electrochemsci.org). This article is an open access article distributed under the terms and conditions of the Creative Commons Attribution license (http://creativecommons.org/licenses/by/4.0/). 